\section{$\underset{\substack{\text { hommes } \\ \text { \& migrations }}}{ }$}

\section{Hommes \& migrations}

Revue française de référence sur les dynamiques

migratoires

\section{$1321 \mid 2018$}

Les mots de l'exil dans l'Europe du XIXe siècle

\title{
Linda Lê, Héroïnes
}

Paris, Christian Bourgois, 2017, 218 pages, $19 €$.

\section{Mustapha Harzoune}

\section{(2) OpenEdition}

1 Journals

\section{Édition électronique}

URL : http://journals.openedition.org/hommesmigrations/4619

DOI : 10.4000/hommesmigrations.4619

ISSN : 2262-3353

\section{Éditeur}

Musée national de l'histoire de l'immigration

\section{Édition imprimée}

Date de publication : 1 avril 2018

Pagination : 184-185

ISBN : 978-2-919040-41-4

ISSN : 1142-852X

\section{Référence électronique}

Mustapha Harzoune, "Linda Lê, Héroïnes », Hommes \& migrations [En ligne], 1321 | 2018, mis en ligne le 01 avril 2018, consulté le 08 janvier 2021. URL : http://journals.openedition.org/hommesmigrations/ 4619 ; DOI : https://doi.org/ERREUR PDO dans /localdata/www-bin/Core/Core/Db/Db.class.php L.34 : SQLSTATE[HY000] [2006] MySQL server has gone away 


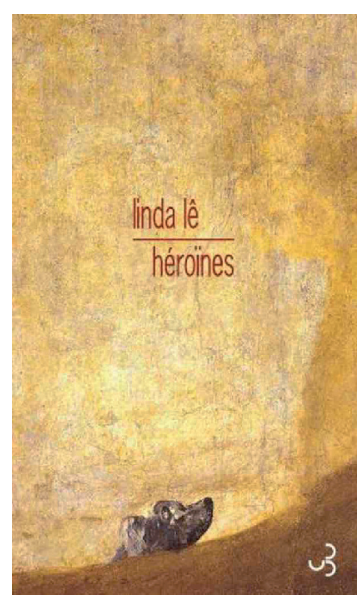

ง

\section{Linda Lê}

Héroïnes

Paris, Christian

Bourgois, 2017, 218

pages, $19 €$

«L Le vrai roman serait (...) comme une autobiographie du possible, c'est-àdire qu'il ne rendrait pas compte, avec une obtuse fidélité, de ce qui a eu lieu dans la réalité, mais ouvrirait la voie à tout ce qui est en devenir, sur le point d'éclore de se réaliser en subissant une transmutation. C'est une espèce d'al-chimie qui consiste à travailler la matière même des faits tangibles jusqu'à ce que la mise en oeurre soit avanttout unfran-chissement defrontière, un saut qui pro-jette vers cet ailleurs où il importe de tendre loreille aux murmures de la bouche d'ombre, en ayant la certitude de n'être pas à l'abri d'une déflagration inté-rieure. " Cette citation est extraite de Chercheurs d'ombres, un recueil de textes également signé Linda Lê (Bourgois, 2017). Dire que le monde change est une chose. En rendre compte dans le 
mouvement même de la création en est une autre. En faire la matière de ses mots et de ses phrases est autrement risqué. L'expérience du roman comme "une autobiographie du possible » est justement la matière d'Héroïnes.

Elles sont trois femmes dont le portrait émerge du méli-mélo des trajectoires, des parts d'ombre et des rumeurs, trois existences mêlées : une chanteuse, l'incarnation et la nostalgie des "belles années » du Vietnam de papa, à la réputation sulfureuse, mélange de débauche et de compromissions, réelles ou colportées par les ragots - et objets d'inavouables désirs. L’autre héroïne, «la boiteuse " pour les uns, "la maquisarde" pour les autres, n'a cessé de faire entendre sa voix de résistante, contre le colonialisme d'abord, contre l'indépendance volée ensuite, jusqu'à son exil parisien enfin. Pas sûr qu'il faille pour autant opposer "la mante religieuse " et "la boiteuse ", comme un premier mouvement tendrait à le faire croire. La troisième et dernière héroïne débarque tel un coup de théâtre. Elle est la demi-sœur de la chanteuse, une Cosette en ao dài, un "lys brisé ", l'incarnation de l'innocence malmenée. Les trois héroïnes sont tirées du néant par une correspondance virtuelle, nourrie de brouilles et d'attirances, entre un homme $(V$.) et une femme ("la correspondante»). De cette matière, de cette "alchimie" surgira un improbable et, in fine, un indiscutable horizon, né du possible des bifurcations.
V. est un suisse pur sucre, n'étaient des origines vietnamiennes dont il ignore tout, tant ses parents ont fait de leurs enfants de " purs produits de l'Helvétie ". Thésard spécialiste de Kafka, il est en panne. Il rumine, seul, dans sa chambre, en mode dépressif. «La correspondante » est une "dilettante », photographe par intermittence, traductrice "à sa façon", elle travaillote pour une agence de voyages et une agence immobilière. Le monde s'offre à l'une - elle ne se réfugie pas dans des "mensonges" - quand l'autre, craintif, se cache dans un " cocon protecteur». V. et « la correspondante » appartiennent à ces générations qui portent le poids de l'histoire sans en avoir été des acteurs directs, qui jonglent entre hier et aujourd'hui, les alchimistes - parfois malheureux - des possibles. La découverte et la fascination pour la chanteuse vont conduire V. à fourrager dans le buisson des origines et des appartenances, à « délaisser les certitudes d'un confort qui n'est pas le sien " pour s'exposer au danger d'un "tremblement de terre ». Pour cela, il a besoin de la correspondante. C'est elle qui lui ouvre toutes les portes, l'aide "à se désamarrer " pour, peut-être, en finir avec les fantômes.

Ce qui se joue, est bien une " transmutation", non pas une simple évolution mais un changement de nature qui, d'un besoin de certitudes (idéalisme, intellectualisme), mènent à accepter sa fragilité, ses émotions et accueillir la fragilité du monde. Être "à la croisée des vents".

M. H. 